\title{
The effect of the Euro on country versus industry portfolio diversification
}

\author{
Thomas J. Flavin* \\ Department of Economics, National University of Ireland Maynooth, County Kildare, Ireland
}

\begin{abstract}
We examine the relative benefits of industrial versus geographical diversification in the Euro zone before and after the introduction of the common currency. A priori, one may expect that increased stock market correlation would precipitate a move from geographical towards industrial diversification. We employ the empirical model of Heston and Rouwenhorst but show that adopting a panel data approach is a more efficient estimation method. We find evidence of a shift in factor importance; from country to industry. However, this is not exclusive to the Euro zone but is also present for non-EMU European countries. Therefore, fund managers should pursue industrial rather than geographical diversification strategies.

(C) 2004 Elsevier Ltd. All rights reserved.
\end{abstract}

JEL classification: F36; G11; G15

Keywords: Portfolio diversification; Industry and country effects; Euro

\section{Introduction}

A fundamental principle of financial theory, dating back to Markowitz (1952), is that portfolio diversification allows an investor to earn higher returns for each unit of risk and hence leads to greater portfolio performance. Grubel (1968) and Levy and Sarnat (1970) were among the first to show that diversification across international assets increased these benefits due to their relatively low correlation compared to those of domestic stocks. Many empirical papers find that these benefits are still present despite increasing integration across financial markets in both stock markets (Grauer and Hakansson, 1987; De Santis and Gerard, 1997) and

\footnotetext{
* Corresponding author. Tel.: +353-1-7083369; fax: +353-1-7083934.

E-mail address: thomas.flavin@may.ie (T.J. Flavin).
} 
bond markets (Levy and Lerman, 1988) and in the face of time-varying correlations (Ang and Bekaert, 2002). Many authors have posed the question whether or not equivalent benefits can be obtained from diversifying portfolios across industries rather than across national borders. The early literature provided overwhelming evidence that international diversification is better than industrial diversification. Grubel and Fadnar (1971) report that industries within a country are more highly correlated than industries across countries. However, Heston and Rouwenhorst $(1994,1995)$ were among the first papers to rigorously address this issue. They focus on European markets - 12 in total - and assign each stock to one of seven industrial sectors. Their main finding was that the majority of diversification benefits stem from international rather than industrial diversification. They report that on average less than $4 \%$ of the variation in country indexes is attributable to their industrial composition. Griffin and Karolyi (1998) include developed non-European markets as well as some emerging markets, while allowing for "more finely partitioned industrial classifications" but find no greater importance for industry effects in portfolio selection. Rouwenhorst (1999) again focuses on European countries over the post-Maastricht Treaty time period up to August 1998 and finds that the relative strengths of country effects is unaffected by time and increased economic integration. More recent studies have been less supportive of the view that country effects dominate industrial sectoral effects. Brooks and Catao (2000) estimate the impact of 'new-economy' versus 'old-economy' stocks in portfolio diversification and find that the introduction of 'new-economy' stocks finds an increased role for diversification across industrial sectors. Baca et al. (2000) also report an increased role for sectoral effects in determining asset returns and conclude that country effects have declined in importance. Their focus is on the seven largest world stock markets so therefore you may expect relatively high levels of integration. Moreover, Cavaglia et al. (2000), using an extended sample of countries, agree with this finding and state that for the purposes of portfolio risk reduction, industrial factors are more important than country effects. Recent studies on emerging markets have identified a similar pattern with Wang et al. (2003) finding that industrial effects have been significantly more important than country effects in Asian markets since at least 1999.

Until now, studies focussing on Europe have found that industrial composition plays a relatively minor role in determining country correlations and that low correlations are primarily due to country-specific sources of return variation. This paper focuses on the determination of cross-country correlation and hence on the optimal portfolio diversification strategy from the perspective of an investor from a Euro zone country. In particular, we assess the relative importance of country- and industry-specific shocks to the variability of stock returns. There are a number of legitimate reasons for a re-examination of this issue.

Firstly, from a financial markets perspective, there has been sufficient change in the investment landscape to warrant further investigation. In the aftermath of the introduction of irrevocably fixed exchange rates between member countries on January 1, 1999, a typical investor who wants to hold a portfolio without foreign exchange risk has had their investment opportunity set altered significantly. The 
portfolio set has been expanded enormously as all Euro zone investors may diversify across international borders between participating states without worrying about currency fluctuations. Bodart and Reding (1999) found that exchange rate risk reduces market integration. Of course, the magnitude of the benefits of increasing the investment set will be dictated by the correlations between stocks in these countries. There are likely to be large risk-return benefits to be reaped if the previously observed low country correlations are maintained. However, some of the textbook explanations for low correlation no longer apply to the Euro zone countries, such as differences in fiscal and monetary policies. All states have now transferred responsibility for monetary policy from domestic central banks to the European Central Bank (ECB), while the degree of fiscal autonomy among member countries has also been dramatically reduced. This policy co-ordination has led to a substantial narrowing of interest rates across the Euro zone countries. We should expect that increased economic integration would reduce the asymmetry of responses to shocks to fundamental variables. Furthermore, few institutional or legal impediments remain. Consequently, one might expect that cross-country correlations would be mainly driven by differences in the industrial structure of domestic markets. Therefore, it is reasonable to expect that diversification across industries may be more important in this new era, especially since Carrieri et al. (2004) find that increased country level integration does not rule out industry-level segmentation. However, there are a number of factors that could work in the opposite direction. Goetzmann et al. (2002) find that episodes of integration are not only characterised by increased cross-country correlation but also by an expansion of the investment opportunity set. The latter effect may offer improved investment diversification possibilities. Another competing view comes from Francis et al. (2002) who show that above average levels of currency volatility leads to increased stock market correlation, so it is possible that the effect of eliminating exchange rate variability could result in lower correlation between markets. The adoption of the Euro provides as near to a natural experiment as you are likely to find in financial economics and allows us to assess the potential explanations of low crosscountry correlations mentioned above.

Secondly, from an econometric viewpoint, we also apply more efficient estimation techniques to the model than those usually employed. In particular, we form a panel data set and show that pooling the data and estimating a cross-section of time series regression leads to more precise estimation. This allows us to attach statistical as well as economic significance to our results and has important implications for fund managers in making their decision whether to pursue active geographical or industrial diversification.

We find that there has been a shift in importance from country to industrial effects. In the early years of our sample, our results are consistent with the other literature focussing on European stock markets; country effects outweigh industrial effects. However, this result is reversed following the introduction of the Euro. Therefore, Euro zone investment strategies would be better off concentrating on industrial rather than geographical diversification. This is consistent with increased integration between Euro zone markets after the adoption of the single currency, 
which has been documented by Fratzscher (2001). However, we use a group of non-EMU European countries to show that this result is not just confined to the Euro zone. The robustness of our results to the inclusion of these additional markets suggests that the decline in importance of country effects may be due to factors other than the introduction of the Euro. In particular, when taken with the other literature, increased country correlations appear to be a global phenomenon. The remainder of the paper is organised as follows. Section 2 reviews the literature on the sources of low cross-country correlation and analyses whether these are likely to apply within the common currency area. Section 3 describes the data while section 4 outlines the model and discusses its estimation. Our results are presented in Section 5, while conclusions are contained in Section 6.

\section{Sources of low cross-country correlation}

Given its importance in portfolio selection models, the sources of low crosscountry correlation of financial asset returns have generated a great deal of literature. A number of common themes have emerged.

Firstly, a potential explanation of low correlation may be due to low levels of market integration. In segmented or partially segmented markets, local factors may be more important than global factors. Without full integration, it is possible to observe pricing differences or different speeds of price adjustment. There is empirical evidence to show that stock market correlation is positively linked to levels of both economic and financial integration. Ferson and Harvey (1991) find a positive relationship between the degree of real and financial integration. Bekaert and Harvey (1995) show that market integration has a strong influence on the co-movement of emerging market returns with a global market factor. Furthermore, there is evidence of market integration increasing over time (De Santis and Gerard, 1997; Hardouvelis et al., 1999). Reductions in transaction costs, institutional and legal impediments are generally credited with increasing integration among developed markets. Following the substantial political, economic and financial co-ordination within the Euro zone, stock market co-movements are unlikely to be low for lack of market integration.

However, stock market integration may still be restricted by the home bias in equity portfolios displayed by many investors (see Lewis, 1999 for a review of this topic). One possible explanation of this phenomenon is that investors are better informed about domestic (or regional) market conditions or they are more optimistic about the future performance of domestic markets (investor sentiment). Flavin et al. (2003) show that geographical variables, which may be a proxy for these psychological barriers, have significant explanatory power for determining the level of stock market correlation.

Secondly, following Roll (1992), differences in the industrial composition of national indices have been put forward as an important determinant of crosscountry correlation. However, more recent empirical evidence does not support this view. Heston and Rouwenhorst (1994, 1995), Griffin and Karolyi (1998) and 
Flavin et al. (2003) all show that industrial composition explains little of stock market co-movements.

Thirdly, economic fundamentals and economic shocks may also play a role in determining stock market correlation. Campbell and Hamao (1992) show that economic fundamentals, such as interest rates and dividend yields, help to explain US and Japanese market co-movement. Conversely, Karolyi and Stulz (1996) find little evidence that macroeconomic announcements or shocks to exchange rates or interest rates influence US and Japanese stock return correlations. Ammer and Mei (1996) find that equity risk premia rather than fundamental variables account for most co-movements across national indices. Obviously, country-specific shocks will impact on domestic market returns and hence reduce co-movements with other markets, but also global shocks to which markets have different sensitivities may also result in low cross-country correlation.

With the co-ordination of monetary variables within the Euro zone, the main focus of our paper is to examine the role of economic shocks, the final explanation outlined above. In particular, we seek to assess the relative importance of countryand industry-specific shocks. The degree to which such shocks have differential cross-country and cross-industry effects may help to identify the optimal diversification strategy available to a portfolio manager.

\section{Data}

We use monthly total returns and market capitalisations on 1193 companies across the 11 original members of the 'Euro zone'. Greece is omitted from the analysis, as it did not join the EMU on January 1999. A control group is created using similar data for the UK, Switzerland, Denmark and Sweden. All returns are expressed in a common currency, the Euro. Pre-Euro returns for all markets and post-Euro returns for the non-EMU countries are computed by converting from the domestic currency to the Euro via the ECU end-of-month exchange rate. Our sample stretches from January 1995 to December 2002. The starting point was chosen to give an equal span before and after the introduction of the Euro. In this respect, we hope to capture changes in optimal diversification strategies that may have been induced by the adoption of the common currency. All data are collected from Datastream and each company is assigned to an industrial sector and a country according to the Datastream classification. These are consistent with the FTSE industry sectors. In this application, we use ten broad industrial classifications. Griffin and Karolyi (1998) have already shown that using very fine industry definitions does not significantly change the findings. Given that we are trying to assess the impact of the introduction of the common currency, we have decided to work with a balanced panel of companies. For the Euro zone, this leaves us with 740 companies. The industrial and geographical breakdown of these companies is reported in Table 1. It is clear that there is a non-uniform distribution of companies across industrial sectors and especially across geographical boundaries, e.g. Luxembourg has relatively few stocks and these tend to be concentrated in the 


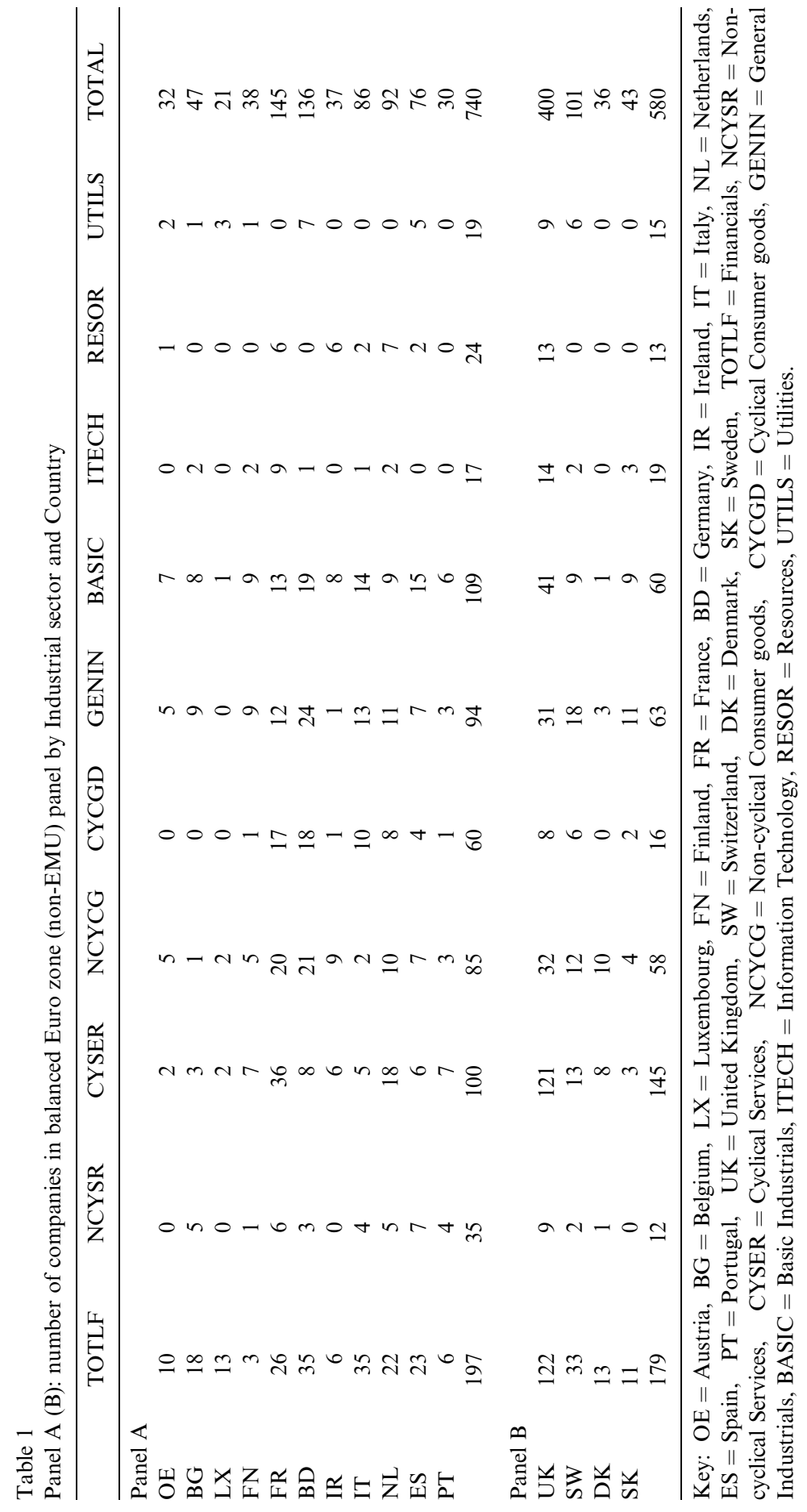


financial sector, whereas Germany accounts for almost $20 \%$ of the companies in our sample but $75 \%$ of these operate outside of the financial sector.

Table 2 presents information on the average market capitalisation of the firms in our sample. In particular, we report the average proportion of the Euro zone market that is attributable to each country and each sector over the whole sample. Again we see important differences across countries and industrial sectors. Information technology stocks accounted for about $7 \%$ of the Euro zone value-weighted index but almost $40 \%$ of these were located in Finland (mainly Nokia). These stocks represented over $60 \%$ of the Finnish market. The highest value weights for German stocks are in Financials and Industrial firms, while France has a higher concentration of Service providing companies.

Tables 3 and 4 present sample correlations for the Euro zone countries and industries, respectively. These correlations are computed using monthly returns for the pre- and post-Euro period. Initially, focusing on the country correlations, we can see that there is significant variation between the samples. The average pairwise correlation falls from 0.679 in the pre-Euro sample to 0.586 in the post-Euro sample. This is counter-intuitive given that we would have expected the correlation to rise in light of the increased integration within this economic zone. However, this finding is consistent with Adjaoute and Danthine (2004) who argue that this could be due to the cyclical nature of country correlation. We would require an extended post-Euro sample to verify this. Another potential explanation is that EMU has created even greater return dispersion through an expansion of the investment opportunity set as suggested by Goetzmann et al. (2002), thereby offsetting the integration effect with new diversification possibilities. Alternatively, it may be that the elimination of currency volatility has lowered equity market correlation, in line with Francis et al. (2002). The falling average correlation does mask the fact that over $38 \%$ (21 out of 55 ) of the correlations did increase. Table 4 contains the corresponding matrix for the Euro zone industries. Here, we see a relatively large decrease in the average pair-wise correlation, from a pre-Euro level of $0.747-0.568$ in the post-Euro sample. A decrease in correlation was recorded in 38 of the 45 (nearly $85 \%$ ) correlation coefficients. It is noteworthy that the average correlation is higher for industries than countries in the former time period and slightly lower in the later period. This suggests that there may have been a relative shift or, at least, convergence in country and industry effects over the sample.

Equivalent correlations for the non-EMU sample are both characterised by increasing correlation. Average correlations have increased from 0.668 to 0.704 for countries and $0.428-0.453$ for industries. It is noticeable that all pair-wise crosscountry correlations are much higher than those for industries. These correlations are presented in Tables 5 and 6.

\section{Methodology}

Heston and Rouwenhorst (1994) propose a model of stock return that is capable of disentangling country and industry effects. Solnik and de Freitas (1988) allow 


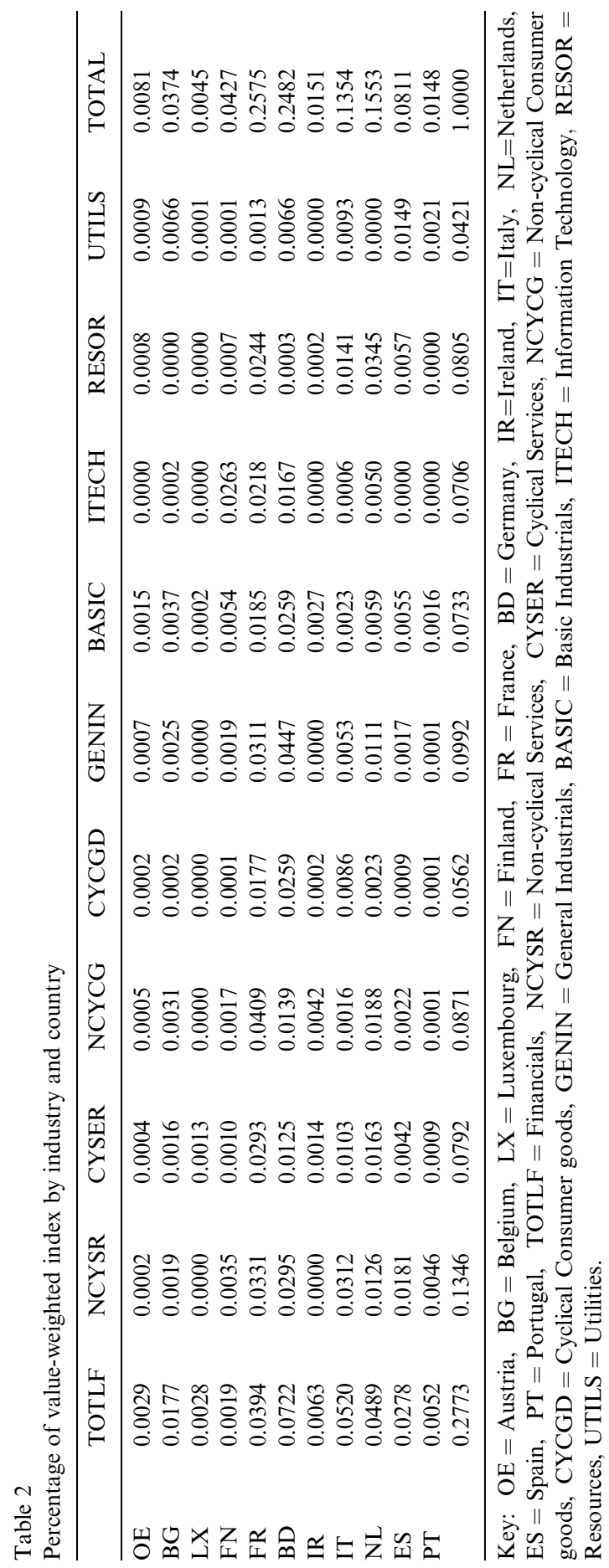




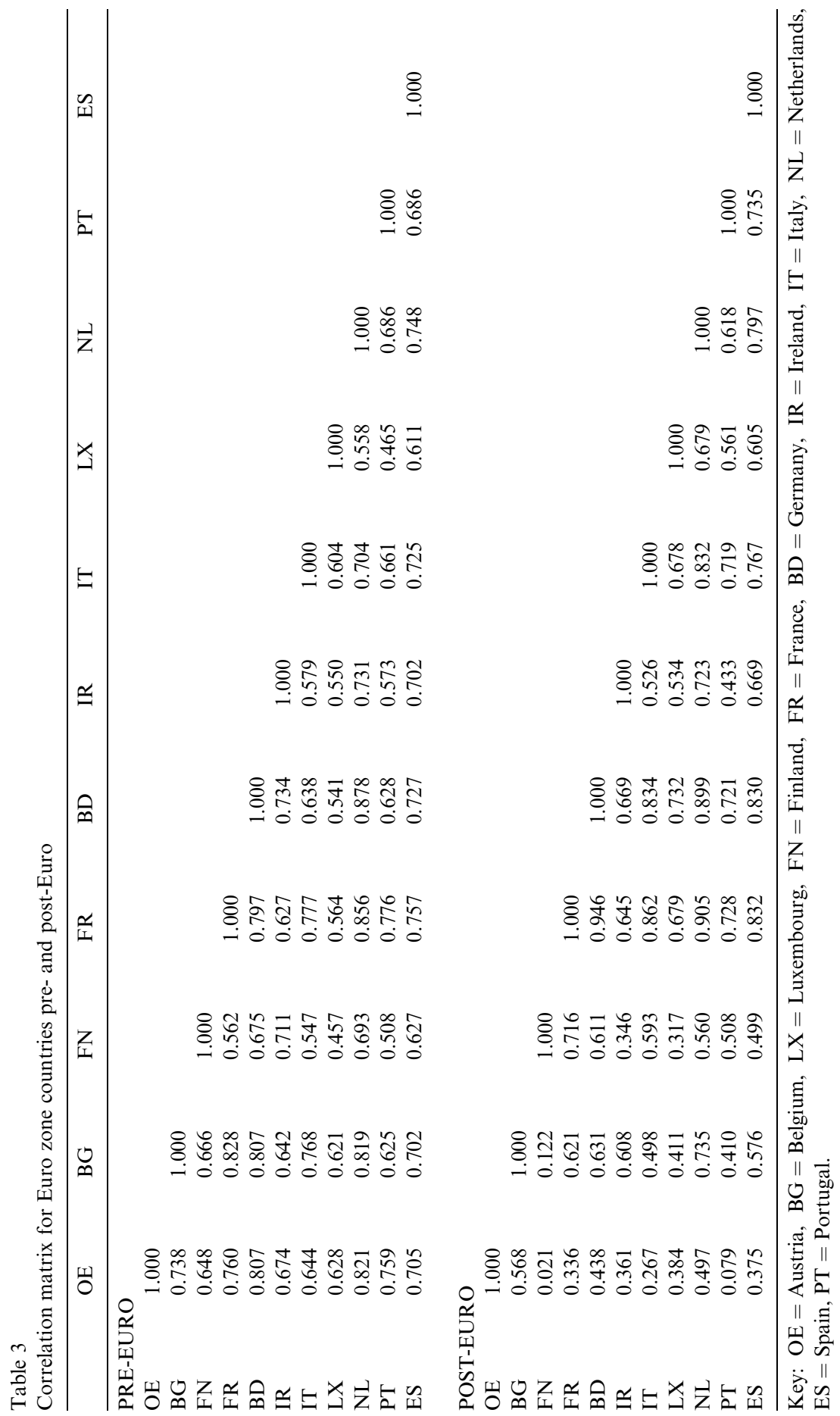




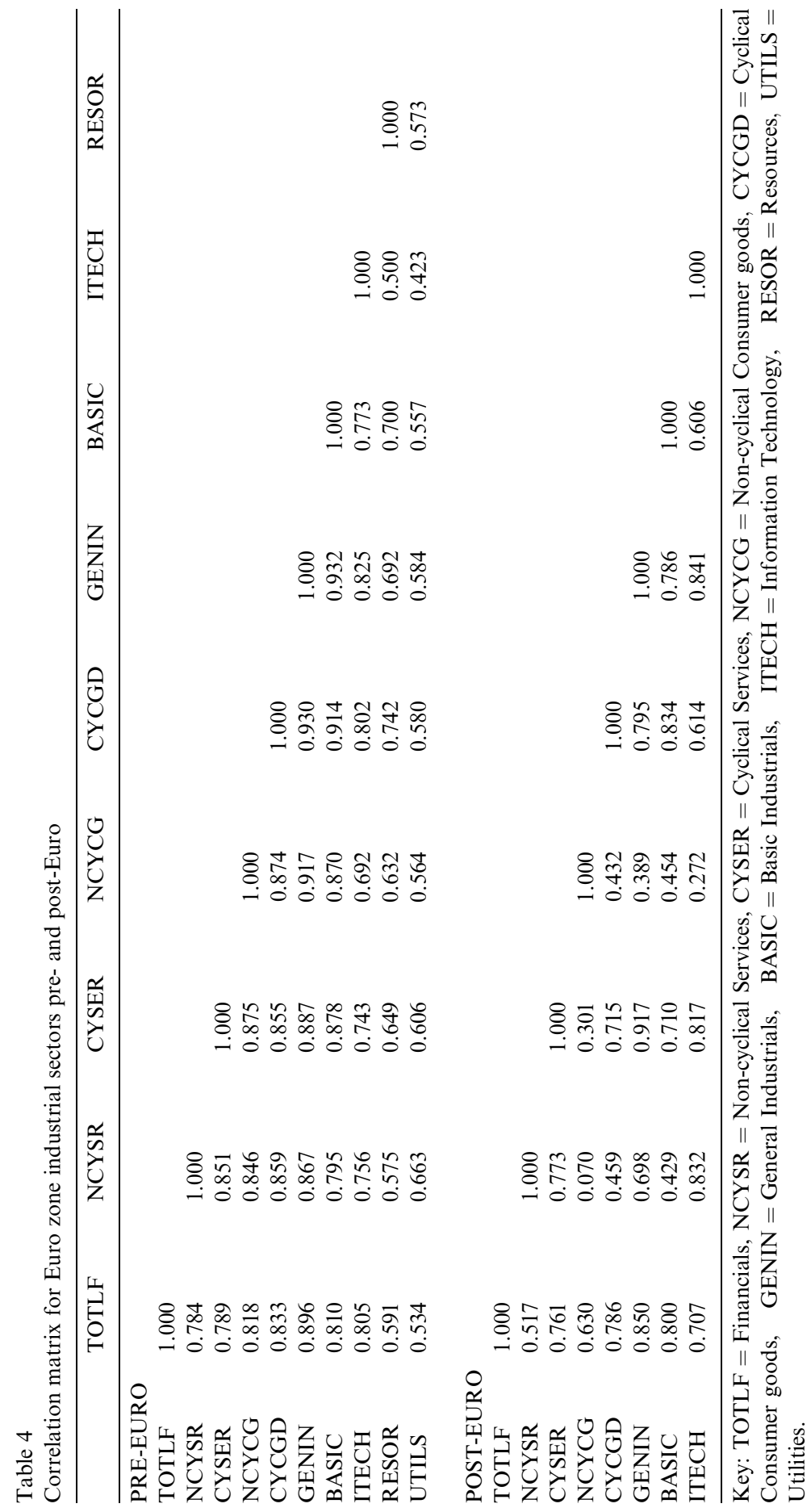


Table 5

Correlation matrix for non-EMU countries pre- and post-Euro

\begin{tabular}{lllll}
\hline $1995-1998$ & & & & \\
\hline & UK & SW & DK & SK \\
\hline UK & 1 & 1 & & \\
SW & 0.639548 & 0.657548 & 1 & 1 \\
DK & 0.728706 & 0.690473 & 0.616662 & \\
SK & 0.677344 & & & \\
$1999-2002$ & & & & 1 \\
UK & 1 & 1 & 1 & 1 \\
SW & 0.790238 & 0.677749 & 0.708063 & \\
DK & 0.685414 & 0.632709 & & \\
SK & 0.731875 & & & \\
\hline
\end{tabular}

Key: UK $=$ United Kingdom, SW $=$ Switzerland, DK $=$ Denmark, SK $=$ Sweden.

for exchange rate effects, but this is clearly redundant in our specification. The return for any stock $i$ that belongs to industry $j$ and country $k$ is given by:

$$
R_{i t}=\alpha+\beta_{j}+\gamma_{k}+\varepsilon_{i t} .
$$

In this formulation, $\alpha$ represents a common component of all stocks, $\beta_{j}$ captures the industry effect and $\gamma_{k}$ the country effect. The error term, $\varepsilon_{i}$, is asset specific and is assumed to be zero mean with a finite variance. This specification rules out any interaction between industry and country effects. Using our data, we have companies located in one of 11 countries $(k=1-11)$, with each belonging to one of ten industries $(j=1-10)$. We define industry dummies, $I_{i j}$ to have a value of one if stock $i$ belongs to industry $j$ and zero otherwise. Likewise, country dummies, $C_{i k}$, take a value of one if stock $i$ belongs to country $k$ and zero otherwise. Thus, we can rewrite Eq. (1) for each time period as

$$
R_{i t}=\alpha+\beta_{1} I_{11}+\cdots+\beta_{10} I_{i 10}+\gamma_{1} C_{i 1}+\cdots+\gamma_{11} C_{i 11}+\varepsilon_{i t} .
$$

Of course, Eq. (2) cannot be estimated in its current form as both the industry and country dummies sum to unity, resulting in perfect multicollinearity between the regressors. We could proceed by dropping an arbitrary industry and country and measuring everything else relative to these. However for portfolio managers, it would be more desirable to measure country and industry effects relative to some more easily identifiable and accepted benchmark such as an equally (or value)weighted index of stocks. Heston and Rouwenhorst (1994) follow Suits (1984) and Kennedy (1986) by estimating a constrained dummy variable regression. In essence, this amounts to constraining the weighted industry and country effects to sum to zero. Imposing such restrictions is equivalent to measuring each industry relative to the average firm or in this case a weighted portfolio of Euro zone stocks. If we apportion the weights simply as the number of stocks in each country 


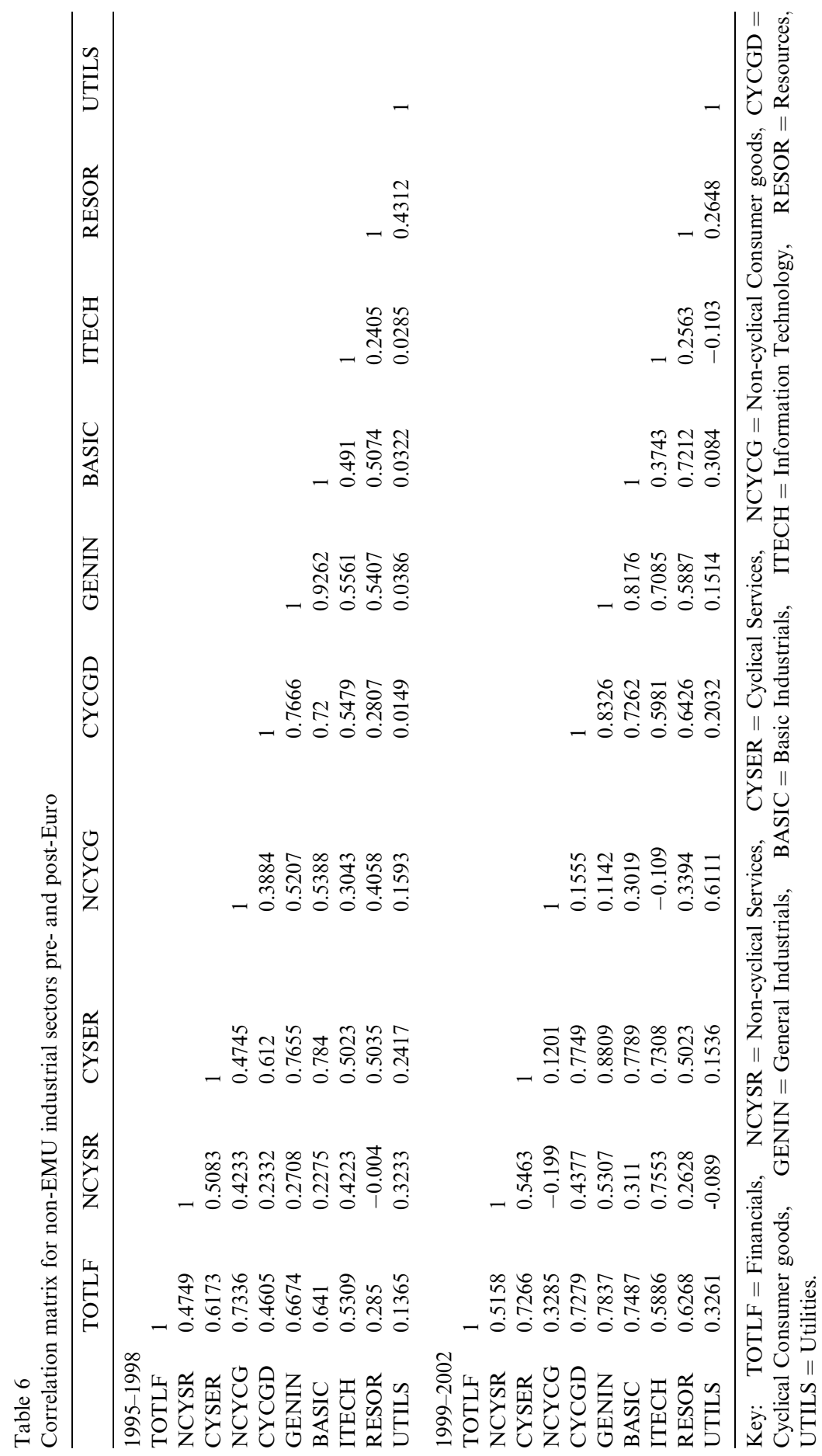


and industry, then our benchmark is an equally weighted index.

$$
\sum_{j=1}^{10} n_{j} \beta_{j}=0, \sum_{k=1}^{11} m_{k} \gamma_{k}=0
$$

where $n_{j}$ and $m_{k}$ represent the number of firms in industry $j$ and country $k$, respectively.

Alternatively weighting the industries and countries by the proportion of the total Euro zone market that they account for allows us to measure relative to a value-weighted portfolio of stocks.

$$
\sum_{j=1}^{10} \delta_{j} \beta_{j}=0, \sum_{k=1}^{11} \varphi_{k} \gamma_{k}=0
$$

where $\delta_{j}$ and $\varphi_{k}$ are the value weights of industry $j$ and country $k$, respectively.

Heston and Rouwenhorst (1994, 1995)), Griffin and Karolyi (1998), Rouwenhorst (1999) and Baca et al. (2000) all use a similar estimation technique. They estimate a cross-section regression for each month of the sample. This generates a time series of industry and country effects, which are then averaged to produce estimates of the effects over the period. Though these estimates are unbiased, they are nonetheless inefficient. Their estimation technique tends to over-estimate the coefficient standard errors, often resulting in estimates that are not statistically different from zero. Therefore, we propose to form a pooled regression and estimate the following equation,

$$
R_{i t}=\alpha+\beta_{1} I_{i 1, t}+\cdots+\beta_{10} I_{i 10, t}+\gamma_{1} C_{i 1, t}+\cdots+\gamma_{11} C_{i 11, t}+\varepsilon_{i t} .
$$

We must take account of the fact that our error term may have a non-constant variance in our pooled dataset. In particular, it may be higher for some firms than for others (individual effects) or in some time periods relative to others (time effects). Given the time invariance of the regressors, the solution to this problem is to estimate a 'random effects' model. The error term, $\varepsilon_{i}$, may be decomposed into a purely random component, a firm-specific effect and a time effect. We find that allowing for both these effects eliminates heteroscedasticity in the error term and the model is then estimated by generalised least squares (GLS).

\section{Results}

Our analysis focuses on whether portfolio managers should concentrate on geographical or industrial portfolio diversification. We also seek to address the question of what effect the introduction of the Euro has had on the optimal diversification strategy. Firstly, we look at the evidence over the whole sample, January 1995-December 2002. Following Heston and Rouwenhorst (1995) and Rouwenhorst (1999), we calculate the relative strength of country and industry effects as the average absolute deviation from a benchmark portfolio. Tables 7 and 8 present our estimates relative to an equally- and value-weighted Euro zone 
Table 7

Country and industry effects on equally weighted portfolio 1995-2002

\begin{tabular}{lcllllll}
\hline Industry & $\beta$ & $\mathrm{SE}(\mathrm{P})$ & $\mathrm{SE}(\mathrm{CS})$ & Country & $\gamma$ & $\mathrm{SE}(\mathrm{P})$ & $\mathrm{SE}(\mathrm{CS})$ \\
\hline TOTLF & $0.168^{* *}$ & 0.063 & 1.21 & $\mathrm{OE}$ & -0.261 & 0.175 & 2.83 \\
NCYSR & -0.092 & 0.168 & 2.12 & $\mathrm{BG}$ & 0.029 & 0.144 & 2.26 \\
CYCSR & 0.001 & 0.096 & 1.48 & $\mathrm{FN}$ & $0.478^{* *}$ & 0.160 & 3.12 \\
NCYCG & 0.166 & 0.104 & 1.77 & FR & $0.147^{*}$ & 0.077 & 1.73 \\
CYCGD & 0.014 & 0.126 & 1.57 & BD & $-0.256^{* *}$ & 0.079 & 1.72 \\
GENIN & $-0.191^{*}$ & 0.098 & 1.35 & IR & 0.044 & 0.165 & 3.12 \\
BASIC & $-0.214^{* *}$ & 0.090 & 1.45 & IT & 0.027 & 0.103 & 4.34 \\
ITECH & -0.289 & 0.244 & 7.89 & LX & $-0.655^{* *}$ & 0.220 & 2.65 \\
RESOR & -0.301 & 0.206 & 3.28 & NL & -0.132 & 0.098 & 1.64 \\
UTILS & $0.440^{*}$ & 0.232 & 2.99 & PT & 0.205 & 0.181 & 3.32 \\
Av Abs & 0.188 & & & ES & $0.238^{*}$ & 0.126 & 2.87 \\
\hline
\end{tabular}

* Signifies that the estimated coefficient is statistically significant at 5\% (10\%) level.

** Signifies that the estimated coefficient is statistically significant at 5\% $(10 \%)$ level.

portfolio, respectively. Both sets of results convey a consistent story so we will mainly discuss the results measured relative to the equally weighted index.

Heston and Rouwenhorst (1995) interpret the $\beta$ 's and $\gamma$ 's as portfolio tracking errors, i.e. the estimated coefficients tell you how much better or worse your portfolio would have performed if you had taken a bet on an individual country or industry. For example, from Table 7 , we can see that if one placed a bet of $10 \%$ more than the European equally weighted portfolio in French equity, keeping the industrial composition the same, then our portfolio would have outperformed the average by 1.5 basis points. On the other hand, a similar wager on Luxembourg stocks would have led to a portfolio underperformance of about 6.5 basis points.

Table 8

Country and industry effects on value weighted portfolio 1995-2002

\begin{tabular}{llllllll}
\hline Industry & $\beta$ & $\mathrm{SE}(\mathrm{P})$ & $\mathrm{SE}(\mathrm{CS})$ & Country & $\gamma$ & $\mathrm{SE}(\mathrm{P})$ & $\mathrm{SE}(\mathrm{CS})$ \\
\hline TOTLF & $0.179^{* *}$ & 0.064 & 1.31 & OE & -0.257 & 0.175 & 3.04 \\
NCYSR & -0.081 & 0.148 & 1.86 & $\mathrm{BG}$ & 0.032 & 0.143 & 2.40 \\
CYCSR & 0.012 & 0.100 & 1.45 & FN & $0.481^{* *}$ & 0.156 & 3.19 \\
NCYCG & $0.179^{*}$ & 0.105 & 2.01 & FR & $0.150^{* *}$ & 0.069 & 1.59 \\
CYCGD & 0.025 & 0.127 & 1.79 & BD & $-0.253^{* *}$ & 0.072 & 1.75 \\
GENIN & $-0.180^{*}$ & 0.100 & 1.47 & IR & 0.047 & 0.165 & 3.23 \\
BASIC & $-0.203^{* *}$ & 0.096 & 1.72 & IT & 0.031 & 0.098 & 4.23 \\
ITECH & -0.278 & 0.224 & 7.52 & LX & $-0.651^{* *}$ & 0.218 & 2.84 \\
RESOR & -0.290 & 0.190 & 3.34 & NL & -0.129 & 0.093 & 1.61 \\
UTILS & $0.451^{* *}$ & 0.221 & 3.04 & PT & 0.209 & 0.179 & 3.51 \\
Av Abs & 0.189 & & & ES & $0.241^{* *}$ & 0.109 & 3.00
\end{tabular}

${ }^{*}$ Signifies that the estimated coefficient is statistically significant at $5 \%$ level.

${ }^{* *}$ Signifies that the estimated coefficient is statistically significant at $10 \%$ level. 
Similarly, over-weighting your portfolio in favour of Utility stocks by $10 \%$, while keeping the country composition constant, would have led to a return of 4.4 basis points in excess of that available on the benchmark. A $10 \%$ wager on either general or basic industrials would have resulted in a poorer performance of about two basis points. The results obtained relative to the value-weighted benchmark are very similar (see Table 8) and consequently, the remainder of the paper concentrates on results relative to the equally-weighted benchmark.

The overall importance of the competing factors can be judged by looking at the average absolute values of the estimated coefficients. Here, we find that the country effect is larger than the industrial effect, 0.225 versus $0.188(0.226$ versus 0.189 for the value-weighted benchmark). Therefore, it appears that there are greater benefits to be reaped from portfolio diversification across countries rather than industries over the entire sample.

However, studies that evaluate country and industry effects by focussing on portfolio tracking errors fail to find any statistical significance for the estimated coefficients. Thus, the hypothesis that the portfolio tracking errors, or deviations from the average portfolio, are equal to zero cannot be rejected. A striking benefit of using a panel data approach is in the relative precision of our results. The pooled regression generates much more precise estimates than averaging over individual cross-sections. While the estimates of $\beta$ 's and $\gamma$ 's are the same, the standard errors from the pooled regression are smaller, by a factor of between 10 and 20, than the corresponding errors from averaging over cross-sections. In Tables 7 and 8, this can be clearly seen from comparing the standard errors from our panel approach, labelled SE(P), with those generated by adopting the alternative technique, SE(CS).

While Heston and Rouwenhorst (1995) and other studies that employ the latter estimation technique are able to offer an economic interpretation to their estimated coefficients, all of these parameters are statistically indistinguishable from zero. Therefore, a fund manager cannot be confident that any of the deviations in performance relative to the chosen benchmark will materialise. However, forming a panel dataset and estimating a 'random effects' model produces many parameters that are significantly different from zero and thus have statistical as well as economic meaning. ${ }^{1}$ For example, at conventional confidence levels, we can predict that French, Spanish and Finnish equities will out-perform the equally weighted Euro zone index, while over-weighting German and Luxembourg stocks leads to a poorer portfolio return. Likewise, we are confident that increased holdings of financial and utility stocks lead to superior performance relative to the equally weighted index while increased holdings of general and basic industrial stocks would have led to under-performance.

While we could split our sample into pre- and post-Euro samples and attempt to deduce the effects of the introduction of the common currency from those alone, it

\footnotetext{
${ }^{1}$ In Tables 7 and 8, the starred and double-starred variables are significant at the $5 \%$ and $10 \%$ levels, respectively, when estimated using the panel data approach. None of the estimated coefficients are statistically significant when the alternative estimation technique is employed.
} 
is much more informative to look at country and industry effects over many different samples. From the start of our sample, the advent of the Euro was well documented and consequently, its effects should not be expected to manifest themselves only in the post-1999 sample. Therefore, we estimate our model for all combinations of periods beginning in January and ending in December. We summarise our results in Table 9. In particular, we present a ratio of Industry to Country effects for all periods. A ratio greater (less) than unity indicates that industry (country) effects were relatively more important in that period.

There are a number of noteworthy features. In periods that span the introduction of the Euro, results suggest that country effects have, in general, been more important. Obvious exceptions to this are samples ending in December 1999. However, differences between samples before and after the adoption of the single currency are more informative.

Focussing on the north-western quadrant where all ratios are based purely on pre-Euro data, we see country effects were dominant in all periods up to and including 1997. This is consistent with the findings of Rouwenhorst (1999). However in samples that include 1998 returns, industry effects are starting to dominate. In contrast, the purely post-Euro sample, located in the south-eastern quadrant, suggest that in this later time period, industry effects have become relatively more important than country effects. In all but two of the periods analysed, industry effects dominate. We did observe, in Tables 3 and 4, that, on average, both country and industry effects were characterised by declining pair-wise correlations. However, this phenomenon was more widespread within the Industrial stocks. Furthermore, of the 21 increasing correlation coefficients, the majority of these involved the larger Euro zone countries of France, Germany and Italy, who have the greatest representation in both the equally- and value-weighted indices. This may account for the growth in importance of industry effects in the post-Euro sample.

Based on these results, it is tempting to conclude that the introduction of the Euro and the increasing importance of industrial over geographical diversification within the single currency area are linked. The co-ordination of monetary and fiscal policies, the absence of exchange rate fluctuations and the elimination of institutional impediments have led to increased cross-country integration, especially of

Table 9

Ratio of industry to country effects based on balanced panel of 740 companies from EMU countries

\begin{tabular}{lllllllll}
\hline End $\backslash$ start & Jan 95 & Jan 96 & Jan 97 & Jan 98 & Jan 99 & Jan 00 & Jan 01 & Jan 02 \\
\hline Dec 95 & 0.8841 & & & & & & & \\
Dec 96 & 0.7572 & 0.7460 & & & & & & \\
Dec 97 & 0.5529 & 0.7552 & 0.6618 & & & & & \\
Dec 98 & 1.4264 & 1.2678 & 0.9804 & 1.4167 & & & & \\
Dec 99 & 1.7615 & 1.3632 & 1.2402 & 1.3913 & 1.1095 & & & \\
Dec 00 & 0.9955 & 0.6240 & 0.5716 & 0.5914 & 0.5723 & 2.0594 & & \\
Dec 01 & 0.7487 & 0.3709 & 0.4255 & 0.5693 & 0.7714 & 2.7839 & 1.0570 & \\
Dec 02 & 0.8345 & 0.4897 & 0.6643 & 0.9066 & 1.0794 & 1.8346 & 1.1215 & 1.0428 \\
\hline
\end{tabular}


the larger markets. While cross-country correlation remains low, it has been surpassed by even lower cross-industry correlation. Therefore, it would appear that optimal diversification strategies within the Euro zone would be better concentrated on active industrial sector strategies rather than the more traditional country portfolio approach.

However, we must address the question of whether or not this finding can be attributed to the introduction of a common currency and the associated elimination of exchange rate risk within the Euro zone. After all, Wang et al. (2003) have found similar evidence from Asian markets. We undertake a similar analysis on a group of European markets that have remained outside the single currency area, namely, the UK, Switzerland, Sweden and Denmark. With the exception of Switzerland, all of these are part of the European Union. Panel B of Table 1 presents information on the distribution of the number of companies in this sample. There are 580 companies in total, with the UK being the largest market. Table 10 presents industry to country effects for these markets. Despite the presence of currency risk in their returns, industrial diversification is even more strongly supported for these markets. Again samples prior to 1998 are characterised by the relative dominance of country effects. However, all samples that include post-Euro data point forcefully to the superiority of industry effects. These ratios are much larger than those recorded for the Euro zone, suggesting that industrial diversification is even more beneficial in forming a portfolio of non-EMU European stocks. This finding is consistent with the correlation matrices presented in Tables 5 and 6 .

Of course, it could be argued that given the size of the UK market relative to the others in this group, that country effects might be restricted. Therefore, we conduct the analysis once more for a pan-European portfolio, i.e. including companies from both within and outside of the Euro zone. This gives a potential investor access to the largest possible set of European markets. Our panel now spans 15 countries and consists of 1320 companies. The results follow the same pattern as those for the Euro zone area with the industry effects being just a little larger on average. The complete set of ratios is presented in Table 11.

Table 10

Ratio of industry to country effects based on balanced panel of 580 companies from non-EMU countries

\begin{tabular}{lllllllll}
\hline End $\backslash$ start & Jan 95 & Jan 96 & Jan 97 & Jan 98 & Jan 99 & Jan 00 & Jan 01 & Jan 02 \\
\hline Dec 95 & 0.8987 & & & & & & & \\
Dec 96 & 0.5569 & 0.4070 & & & & & & \\
Dec 97 & 0.8107 & 0.8940 & 1.4481 & & & & & \\
Dec 98 & 1.8503 & 3.1094 & 1.5393 & 1.6714 & & & & \\
Dec 99 & 1.7230 & 2.1482 & 2.2693 & 2.5576 & 1.7085 & & & \\
Dec 00 & 1.9787 & 3.2509 & 1.4899 & 1.5752 & 4.2388 & 1.1030 & & \\
Dec 01 & 0.8875 & 0.8771 & 1.2885 & 1.2344 & 1.8959 & 3.2785 & 2.0357 & \\
Dec 02 & 1.6483 & 1.5838 & 5.4728 & 3.4123 & 2.0875 & 3.0090 & 2.1243 & 2.1009 \\
\hline
\end{tabular}


Table 11

Ratio of industry to country effects based on balanced panel of 1320 companies from Europe

\begin{tabular}{lllllllll}
\hline End $\backslash$ start & Jan 95 & Jan 96 & Jan 97 & Jan 98 & Jan 99 & Jan 00 & Jan 01 & Jan 02 \\
\hline Dec 95 & 0.5720 & & & & & & & \\
Dec 96 & 0.5258 & 0.5202 & & & & & & \\
Dec 97 & 0.5263 & 0.7019 & 0.6522 & & & & \\
Dec 98 & 1.6243 & 1.2697 & 1.0905 & 1.5573 & & & \\
Dec 99 & 1.4045 & 1.4199 & 1.3717 & 1.3483 & 0.9530 & & \\
Dec 00 & 0.8722 & 0.8773 & 0.7136 & 0.6711 & 0.6612 & 1.7161 & & \\
Dec 01 & 0.6223 & 0.3946 & 0.4395 & 0.4170 & 0.6440 & 2.4733 & 1.2010 & 1.0803 \\
Dec 02 & 0.9368 & 0.6274 & 0.8083 & 1.0230 & 1.1898 & 1.8569 & 1.2757 & \\
\hline
\end{tabular}

Our final check for the robustness of our findings is to reproduce the results for the Euro zone while omitting the stocks of the Financial sector. As is evidenced from Tables 1 and 2, this sector is by far the largest in terms of both number of companies and market value. It is also a sector that has been directly affected by the introduction of a common currency. We form new panel of 543 companies drawn from the original 11 Euro zone countries and now nine industrial sectors. Table 12 contains the industry to country ratios for this sample. Once more, a similar pattern emerges. Country effects dominate in the purely pre-Euro sample with industry effects assuming this mantle in the post-Euro era. It is true that the industry dominance is slightly decreased by the omission of the financial stocks, though this might be expected given that we are reducing the investment opportunity set.

Therefore, we must conclude that there has been a shift in the relative importance of country and industry effects within Europe. Evidence from our early samples is consistent with the earlier studies of Heston and Rouwenhorst (1994, 1995) and Rouwenhorst (1999), with country effects dominating industry effects. This dominance appears to have been reversed in more recent years and especially since 1998. However, we cannot attribute this reversal to the introduction of the Euro, as the finding is also true for European countries that have remained outside of the

Table 12

Ratio of industry to country effects based on balanced panel of 543 companies from EMU excluding financials

\begin{tabular}{lllllllll}
\hline End $\backslash$ start & Jan 95 & Jan 96 & Jan 97 & Jan 98 & Jan 99 & Jan 00 & Jan 01 & Jan 02 \\
\hline Dec 95 & 0.9634 & & & & & & & \\
Dec 96 & 0.8009 & 0.6040 & & & & & & \\
Dec 97 & 0.5914 & 0.7677 & 0.6771 & & & & & \\
Dec 98 & 1.5275 & 1.3004 & 0.9431 & 1.3616 & & & & \\
Dec 99 & 1.8263 & 1.3265 & 1.1920 & 1.3552 & 0.9742 & & & \\
Dec 00 & 0.9459 & 0.6075 & 0.4563 & 0.5112 & 0.5422 & 1.9693 & & \\
Dec 01 & 0.7637 & 0.3163 & 0.2858 & 0.4332 & 0.6872 & 1.9958 & 0.7769 & \\
Dec 02 & 0.7212 & 0.3911 & 0.5626 & 0.7751 & 1.0943 & 1.7869 & 1.0350 & 0.9891 \\
\hline
\end{tabular}


single currency. Therefore, the effect that we capture in the Euro zone sample would appear to be part of a more global phenomenon and not precipitated by the program of greater political and economic integration envisaged by advocates of the adoption of a single currency within Europe. In this respect, our results are in line with the broader literature, which has documented a greater role for industry effects within the G7 countries (Baca et al., 2000) and in Asian markets (Wang et al., 2003).

What could account for the increase in the importance of industry effects? Firstly, it should be noted that market conditions over the pre- and post-Euro samples were quite different. The former time period being characterised by the final years of the bull markets while the later period was quite turbulent with a number of crises and a market crash following September 2001. This may be potentially important. Schwert (1989) has shown that stock market volatility increases during a recession and this could be a factor in the magnitude of the individual effects increasing in the later sample. Secondly, correlations tend to increase in times of large shocks to returns such as a stock market crash (King and Wadhwani, 1990) and therefore may limit the importance of country effects in the postEuro period. Even though, this would appear to be inconsistent with the correlation structures presented in Table 3, correlations involving the larger markets of France, Germany and Italy did tend to increase.

Both Griffin and Karolyi (1998) and Griffin and Stulz (2001) suggest that industry-specific shocks may have a greater impact on industries which produce internationally traded goods. Increasing levels of trade may therefore raise the sensitivity of certain stocks to industry-specific shocks. With greater trade being advocated as a benefit of EMU, it could be argued that this may account for some of the increase in importance of industry effects within the single currency zone.

Brooks and Catao (2000) argue that the increasing importance of the industry factor in their study could be due to the Information Technology sector. It is generally accepted that there was a bubble in this sector during the late-90s, being fuelled by internet companies in the main. However, in our analysis, we are dealing with a balanced panel and therefore only include those stocks for which a full history from 1995 to 2002 is available. Therefore, the influence of short-lived, mispriced companies is greatly reduced, if not totally eliminated.

An alternative explanation for the increased importance of industry factors stems from the cyclical behaviour of country effects (Adjaouté and Danthine, 2004). The decline in country factors may be temporary and if so fund managers should be careful about the absolute adoption of industrial strategies. Presently such strategies seem to offer better diversification possibilities but in so far as country factors are cyclical, this could be reversed again.

\section{Conclusion}

The goal of our paper is to assess the relative importance of country and industry effects in European portfolio diversification and the impact of the Euro on this. 
Many earlier studies have addressed this issue and generally, for European markets, concluded that country effects were greater and consequently diversification along geographical lines was more important for fund managers. Our motivation for undertaking this analysis is two-fold. Firstly, this is the first study to focus exclusively on the Euro zone markets in the post-EMU period. The elimination of foreign exchange risk lifted barriers for investors who are averse to this risk source and as such provided a much-expanded 'domestic' market. The adoption of a common monetary policy and the greater alignment of fiscal policy across member states, together with few legal or institutional barriers to investment served to reduce many of the usual explanations for low cross-country correlation. One remaining plausible explanation is that low stock market co-movement stems from the differing industrial composition of the indexes. Therefore, a priori, one might expect that within this region industrial effects may play a more important role in portfolio choice in the aftermath of the Euro being adopted. Secondly, we apply panel data estimation techniques that improve the efficiency of our results. Compared to the more traditional estimation approach, we are able to attach statistical as well as economic significance to our results.

Using data on the Euro zone markets from 1995 to 2002, our findings suggest that in the purely post-Euro sample industry effects outweigh country effects and hence industrial diversification is more likely to confer greater portfolio performance on the investor. On average, correlations between national stock markets in this area have decreased but by less than cross-industry correlations. It is also noteworthy that correlations vis-à-vis the larger markets actually increased. Now, industrial portfolios appear to be less correlated than country portfolios. Industryspecific shocks create more return dispersion than country-specific shocks and hence offer greater portfolio diversification benefits.

However, further analysis reveals that this change in the relative importance of country and industry effects is not exclusive to the Euro zone. In fact, it is also to be found in a sample of non-EMU European countries whether analysed separately or in a larger pan-European sample. Therefore, we conclude that this reversal in the relative fortunes of country and industry diversification is not due to the introduction of the common currency but is part of a global phenomenon that has also been documented for other regions. Consequently, portfolio managers would be well advised to adopt diversification strategies based on industry portfolios rather than country portfolios.

A number of explanations for the reported increase in the importance of industry effects are suggested. Firstly, global market conditions since 1999 have been turbulent with a number of financial crises and the crash following September 11, 2001. Such events generally tend to increase stock market co-movements. Secondly, industry-specific shocks could become a more important source of return variation as some industries become more exposed to international trade. Thirdly, Adjaouté and Danthine (2004) suggest that the decline in country effects may be due to their cyclical behaviour. A longer post-Euro sample will be needed to verify this. 


\section{Acknowledgements}

I would like to thank Bill B. Francis, Jim Lothian, Maurice Roche, Donal O'Neill and other seminar participants at the XII Tor Vergata Conference in Banking and Finance, NUI Maynooth, the Irish Economic Association and the UCC Macro-Finance Symposium for useful comments and suggestions.

\section{References}

Adjaouté, K., Danthine, J.P., 2004. Portfolio diversification: alive and well in Euroland. Applied Financial Economics, forthcoming.

Ammer, J., Mei, J., 1996. Measuring international economic linkages with stock market data. Journal of Finance 51 (5), 1743-1763.

Ang, A., Bekaert, G., 2002. International asset allocation with regime shifts. Review of Financial Studies 15 (4), 1137-1187.

Baca, S.P., Garbe, B.L., Weiss, R.A., 2000. The rise of sector effects in major equity markets. Financial Analysts Journal 56 (5), 34-40.

Bekaert, G., Harvey, C.R., 1995. Time-varying world market integration. Journal of Finance 50 (2), 403-444.

Bodart, V., Reding, P., 1999. Exchange rate regume, volatility, and international correlations on bond and stock markets. Journal of Inter International Money and Finance 18 (1), 133-151.

Brooks, R., Catao, L., 2000. The new economy and global stock returns. IMF Working Paper no. 00/ 216. Washington, DC.

Campbell, J.Y., Hamao, Y., 1992. Predictable stock return in the United States and Japan: a study of long-term capital market integration. Journal of Finance 47 (1), 43-69.

Carrieri, F., Errunza, V., Sarkissian, S., 2004. Industry risk and market integration. Management Science 50 (2), 207-221.

Cavaglia, S., Brightman, C., Aked, M., 2000. The increasing importance of industry factors. Financial Analysts Journal 56 (5), 41-54.

De Santis, G., Gerard, B., 1997. International asset pricing and portfolio diversification with timevarying risk. Journal of Finance 52 (5), 1881-1912.

Ferson, W., Harvey, C.R., 1991. The variation of economic risk premiums. Journal of Political Economy 99 (2), 385-415.

Flavin, T.J., Hurley, M.J., Rousseau, F., 2003. Explaining stock market correlation: a gravity model approach. The Manchester School 70, 87-106.

Francis, B.B., Hasan, I., Hunter, D.M., 2002. Return-volatility linkages in international equity and currency markets. Bank of Finland Discussion Papers no. 9/2002. Helsinki.

Fratzscher, M., 2001. Financial market integration in Europe: on the effects of EMU on stock markets. European Central Bank Working Paper no. 48. Frankfurt.

Goetzmann, W., Li, L., Rouwenhorst, K.G., 2002. Long-term global market correlations. Working Paper no. 8612, National Bureau of Economic Research, Cambridge, MA.

Grauer, R.R., Hakansson, N.H., 1987. Gains from international diversification: 1968-85 returns on portfolios of stocks and bonds. Journal of Finance 42 (3), 721-739.

Griffin, J.M., Karolyi, G.A., 1998. Another look at the role of the industrial structure of markets for international diversification strategies. Journal of Financial Economics 50, 351-373.

Griffin, J.M., Stulz, R.M., 2001. International competition and exchange rate shocks: a cross-country industry analysis of stock returns. Review of Financial Studies 14, 215-241.

Grubel, H., 1968. Internationally diversified portfolios: welfare gains and capital flows. American Economic Review 58, 1299-1314.

Grubel, H., Fadnar, K., 1971. The interdependence of international equity markets. Journal of Finance $26(1), 89-94$. 
Hardouvelis, G., Malliaropulos, D., Priestley, R., 1999. EMU and European stock market integration. CEPR Discussion Paper no. 2124. London.

Heston, S.L., Rouwenhorst, K.G., 1994. Does industrial structure explain the benefits of international diversification? Journal of Financial Economics 36, 3-27.

Heston, S.L., Rouwenhorst, K.G., 1995. Industry and country effects in international stock returns. Journal of Portfolio Management, 53-58.

Karolyi, G.A., Stulz, R.M., 1996. Why do markets move together? An investigation of US-Japan stock return comovements. Journal of Finance 51 (3), 951-986.

Kennedy, P., 1986. Interpreting dummy variables. Review of Economics and Statistics 68, 174-175.

King, M.A., Wadhwani, S., 1990. Transmission of volatility between stock markets. Review of Financial Studies 3, 5-33.

Levy, H., Lerman, Z., 1988. The benefits of international diversification in bonds. Financial Analysts Journal 44, 56-64.

Levy, H., Sarnat, M., 1970. International diversification of investment portfolios. American Economic Review 60, 668-675.

Lewis, K.K., 1999. Trying to explain home bias in equities and consumption. Journal of Economic Literature 37, 571-608.

Markowitz, H.M., 1952. Portfolio selection. Journal of Finance 7 (1), 77-91.

Roll, R., 1992. Industrial structure and the comparative behavior of international stock market indices. Journal of Finance 47 (1), 3-41.

Rouwenhorst, K.G., 1999. European equity markets and the EMU. Financial Analysts Journal 48, 57-64.

Schwert, G.W., 1989. Why does stock market volatility change over time? Journal of Finance 44 (5), $1115-1153$

Solnik, B., De Freitas, A., 1988. International factors of stock price behavior. In: Khoury, S., Ghosh, A. (Eds.), Recent Developments in International Finance and Banking. Lexington Books, Lexington, MA.

Suits, D.B., 1984. Dummy variables: mechanics v. interpretation. Review of Economics and Statistics $66,177-180$.

Wang, C., Lee, C., Huang, B., 2003. An analysis of industry and country effects in global stock returns: evidence from Asian countries and the US. The Quarterly Review of Economics and Finance 43, $560-577$. 